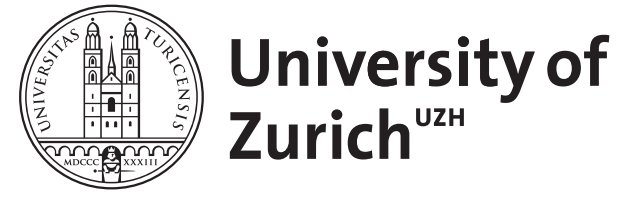
Archive

University of Zurich

University Library

Strickhofstrasse 39

CH-8057 Zurich

www.zora.uzh.ch

Year: 2017

\title{
On the results of clinical studies
}

Papageorgiou, Spyridon N

DOI: https://doi.org/10.1080/14653125.2017.1322324

Posted at the Zurich Open Repository and Archive, University of Zurich

ZORA URL: https://doi.org/10.5167/uzh-149475

Journal Article

Accepted Version

Originally published at:

Papageorgiou, Spyridon N (2017). On the results of clinical studies. Journal of Orthodontics, 44(2):137138.

DOI: https://doi.org/10.1080/14653125.2017.1322324 


\section{STATISTICAL CORNER}

\section{On the results of clinical studies}

Spyridon N. Papageorgiou

Clinic of Orthodontics and Pediatric Dentistry, Center of Dental Medicine, University of Zurich, Zurich, Switzerland

CONTACT Spyridon N. Papageorgiou; snpapage@gmail.com; Clinic of Orthodontics and Pediatric Dentistry, Center of Dental Medicine, University of Zurich, Plattenstrasse 11, Zurich 8032, Switzerland.

Words: 1022

\section{Theoretical scenario}

In the present clinical scenario a group of researchers try to answer by means of a retrospective crosssectional study the following question: "Is lack of antagonist associated with overeruption of unopposed molars in adult patients?". This is of particular interest as molar elongation might lead to difficulties in the prosthetic rehabilitation of the area, possibly required orthodontic intrusion of the molar, or might be associated with loss of periodontal attachment. The authors screened the clinical patient archives of a private practice in order to identify patients having at least one unopposed molar in the maxillary or the mandibular arch due to the loss of its antagonist. A blinded assessor measured from the patient's dental casts the vertical distance of any unopposed molar(s) from the occlusal plane in a qualitative way as (i) no visible overeruption, (ii) overeruption up to $2 \mathrm{~mm}$, and (iii) overeruption more than $2 \mathrm{~mm}$. The assessor received only the plaster model of a single jaw in random order and was therefore blinded to whether a molar had an antagonist or not. Eligible patients were then invited for a clinical examination and the clinical attachment levels of the included molars and their adjacent molar were measured with a periodontal probe as the distance between the cementoenamel junction and the bottom of the periodontal pocket. Attachment loss measurements were categorized as (i) minor: up to $2.0 \mathrm{~mm}$ or (ii) severe: $>2.0 \mathrm{~mm}$.

A total of 55 patients ( 39 women / 16 men) were included in the study with a mean age of 48 years old and a total of 84 unopposed molars (59 upper / 25 lower). After initial descriptive statistics, inferential statistics were used, including chi-square tests to see if molar overeruption categorisation differed between upper or lower molars and to see if molar overeruption was associated with clinical attachment loss. The authors reported that about $80 \%$ of unopposed molars had overerupted (50\% up to $2 \mathrm{~mm} / 30 \%$ more than $2 \mathrm{~mm}$ ), with upper molars being statistically more affected $(P<0.05)$. They also found that unopposed overerupted molars had lower clinical attachment levels than adjacent molars $(P<0.05)$, concluding that overeruption led to loss of clinical attachment.

Which of the following statements is true, if any: 
(a) the measurement method used for molar overeruption was measured reliable

(b) measurements of the study's outcomes were rightly assessed in categories

(c) appropriate statistics were used to analyse the study's results

(d) the study gave evidence that clinical attachment of molars is reduced from overeruption.

\section{Answers}

Statement (a) is false. The measurement method used to assess molar overeruption in the present study is potentially problematic for two reasons. First, molar overeruption and its extent was subjectively ascertained via visual inspection by an assessor. This method is dependent on familiarity with the procedure, calibration, experience from the assessor's side, and might still lead to imprecise or irreproducible measurements. Using an objective measurement method like the scoring of standardized photographs, 3D model scans, or computer tomography pictures with a ruler or an appropriate computer interface would probably lead to more consistent measurements. Second, the occlusal plane that was used as reference plane to assess molar overeruption is not a stable structure that can be reliably used for longitudinal measurements and might be influenced by many factors including the position of the posterior teeth and masticatory movements. Longitudinal measurements made from stable anatomical structures (Björk, 1955) like the anterior palatal vault in the maxilla and the mandibular canal in the mandible might be more appropriate.

Statement (b) is likewise not true. Overeruption of a molar is from its nature a continuous outcomei.e. amount of a molar's supraposition compared to its "ideal" position in $\mathrm{mm}$. By transforming artificially a naturally continuous outcome into categorical we run two dangers. The first is to present the results of the study in arbitrarily-defined groups that are not intuitive and make it difficult to compare the present study with others or combine them in a meta-analysis (Royston et al. 2006). For some few outcomes, widelyaccepted cut-off values exist to form well-defined groups with discrete biological backgrounds or responses. One such example is the categorisation of patients according to their Body Mass Index (BMI) into underweight, normal-weight, overweight, and obese. For most continuous outcomes however, such categorisations do not exist. The second danger of artificially transforming continuous variables to categorical (as is done with molar overeruption and attachment loss here) is the loss of information and the subsequent reduced power for statistical testing. This means that for the analysis of a continuous outcome in categories, we would have to increase our patient sample by around $40 \%$ in order to achieve the same power as for the analysis in continuous format (Zhao and Kolonel, 1992). When statistically analysing the results of studies therefore, it is always preferable to keep continuous measurements - be it response variables (outcomes), exposures, or covariates - in their natural continuous scale (Royston et al. 2006; van Walraven and Hart, 2008).

The third statement is again false. If one carefully reads the study's description it becomes clear that in total 55 patients, but 84 unopposed molars were included in the study. This means that some patients contributed with more than one unopposed molar in the analysis. Multiple molars however within s patient's mouth are not independent, but bound to be correlated (i.e. clustering of observations within a patient), something that has been disregarded in the analysis. Appropriate solutions would be to (i) include only one 
molar from each patient, (ii) to use a more appropriate test like McNemar's test instead of chi-square test, or (iii) use appropriate regression modelling to account for clustering effects (Bland and Altman, 1997).

Finally, statement (d) is also false. The results of the study indicated that overerupted unopposed molars had significantly lower clinical attachment levels than non-overerupted molars. However, this study was cross-sectional in nature and therefore cannot provide evidence for a cause-and-effect relationship between overeruption and attachment loss or vice versa (Hill 1965). They provide only evidence of coexistence. To establish a causal relationship, at the very least two things would be needed. First, a robust longitudinal measurement of attachment levels before and after molar overeruption to assert baseline attachment levels and any attachment loss during the overeruption period. Second, all confounding factors that could play a role in molar overeruption and attachment loss like oral hygiene and periodontal disease should be controlled. This is why prospectively-planned well-controlled longitudinal studies are more suitable to test for causality.

\section{Disclosure statement}

No potential conflict of interest was reported by the author.

\section{ORCID}

Spyridon N. Papageorgiou http://orcid.org/0000-0003-1968-3326

\section{References}

Altman DG, Bland JM. 1997. Statistics notes. Units of analysis. BMJ. 314:1874.

Björk A. 1955. Facial growth in man, studied with the aid of metallic implants. Acta Odontol Scand. 13:9-34. Hill AB. 1965. The environment and disease: association or causation? Proc $R$ Soc Med. 58:295-300.

Royston P, Altman DG, Sauerbrei W. 2006. Dichotomizing continuous predictors in multiple regression: a bad idea. Stat Med. 25:127-141.

van Walraven C, Hart RG. 2008. Leave 'em alone - why continuous variables should be analyzed as such. Neuroepidemiology. 30:138-9.

Zhao LP, Kolonel LN. 1992. Efficiency loss from categorizing quantitative exposures into qualitative exposures in case-control studies. Am J Epidemiol. 136:464-474. 